\title{
Developing a cognitive behavioural therapy model to assist women to deal with HIV and stigma
}

\author{
Jan Tshabalala \\ Department of Psychology, University of Pretoria, South Africa \\ Maretha Visser \\ Department of Psychology, University of Pretoria \\ Maretha.visser@up.ac.za
}

A model of cognitive behavioural therapy (CBT) was developed, implemented, and assessed, in order to assist HIV-positive women deal with HIV and internalised stigma. Interviews with HIVpositive women revealed five common themes in the experience of HIV: feelings of powerlessness; anger and guilt; destructive behaviour; experience of stigma; and uncertainty about the future. These themes were used in the development of an intervention. The intervention was implemented and evaluated. Twenty HIV-positive women were randomly assigned to an experimental group who received eight sessions of individual therapy, and a control group who were placed on a waiting list. Pre- and post-assessments of the two groups were compared using five quantitative scales measuring coping skills, internalised stigma, enacted stigma, self-esteem, and depression. Additionally, a qualitative analysis was made of transcripts of the therapy sessions to explore the effect of various therapeutic techniques. Non-parametric Mann-Whitney tests show that after therapy the experimental group experienced lower levels of depression, internalised stigma and negative coping, and higher levels of self-esteem and positive coping, compared to the control group. Techniques that were effectively used were identified. It is recommended that practising psychologists explore and develop this CBT model with their HIV-positive clients.

Keywords: case studies; cognitive behaviour therapy; cognitive reframing; HIV-related stigma; stigma; women with HIV

Women in developing countries are increasingly becoming infected with HIV\&AIDS (United Nations Programme on HIV \&AIDS, 2007). Various factors contribute to their vulnerability to HIV, including biological and socio-economic factors and culturally defined gender roles. Owing to socioeconomic conditions, women often depend financially on their male partners and are not always in a position to protect themselves from HIV \&AIDS (Ross, 2004; Van Dyk, 2008). The community's acceptance of polygamy allows males to have multiple sexual partners (Abdool Karim, 2005; Mah $\&$ Halperin, 2008). Additionally, there is cultural resistance to condom use (Abdool Karim, 2005), which inevitably contributes to the rising rates of HIV infection and women's risk of contracting HIV even from their long-standing partners (Ross, 2004).

The HIV \& AIDS epidemic has from the beginning been accompanied by stigmatisation of, and discrimination against, people living with HIV\&AIDS and their families (Parker \& Aggleton, 2003). Stigma is a broad and multidimensional concept that focuses on deviation from an ideal or expectation. It also contributes to a powerful discrediting social label that radically changes the way individuals see themselves and how they are viewed as persons (Deacon, Stephney, \& Prosalendis, 2005; Goffman, 1963; Siyam'kela, 2004). The stigmatised attribute is not inherently deviant, but the deviance derives from culturally imbedded meanings in the context. Stigmatisation related to HIV \& AIDS ranges from subtle discriminatory actions to the most extreme degradation and rejection (Bond, Chase, \& Aggleton, 2002; Skinner \& Mfecane, 2004). Stigmatisation is seen as the greatest challenge to slowing the spread of HIV \&AIDS, because it perpetuates the culture of silence and fear that surrounds the disease and prevents individuals from testing and seeking health care.

Stigma exists in various forms:

1. Internalised or felt stigma refers to the stigmatised person's experience or fear of being stig- 
matised. Affected persons often accept some of the negative social judgements that label and discredit them. This is a belief system that can result in secrecy about the diagnosis (Siyam'kela, 2004);

2. Enacted stigma refers to the actual experiences of stigmatisation and resulting incidences of discrimination (Goffman, 1963);

3. Perceived community stigma refers to a generalised perception of community attitudes (Green, 1995).

Recent research among HIV-positive women in South Africa showed that they perceived communities to be highly prone to stigmatisation, more than community members regard themselves to be (Visser, Kershaw, Makin, \& Forsyth, 2008). W omen also reported high levels of internalised stigma, although they did not report high levels of enacted stigma (Rohleder \& Gibson, 2006; Visser et al., 2008). The relationship between different forms of stigma can possibly be explained through the argument of Scambler and Hopkins (1986) that internalised stigma often precedes, rather than results, from enacted stigma. They claim that because of high levels of perceived community stigma, affected persons fear to reveal their status because they expect others to reject them, irrespective of the actual level of enacted stigma in the community. Because of high levels of internalised stigma, many individuals reduce the opportunities for enacted stigma by not disclosing their status, in order to protect themselves from discriminatory actions. This can obviously be psychologically damaging for the infected person.

Common reactions to an HIV-positive diagnosis are feelings of self-blame, shame, powerlessness, worthlessness, withdrawal from social interaction and depression (Mokhoka, 2000; Santana \& Dancy, 2000). In a South African study involving 317 HIV-positive women, it was found that $43 \%$ of the women experienced high levels of depression (Makin, Forsyth, Visser, Sikkema, Neufeld, \& Jeffery, 2008). Depression was four times more likely in HIV-positive women than among noninfected women (Morrison, Petitto, Ten Haven, Gettes, Chiappini, \& Weber, 2002). From the literature it can be concluded that the negative emotional experiences of women with HIVare largely affected by the misconception that HIV is a death sentence and the internalisation of stigmatising attitudes which results in the expectation of being socially isolated and rejected (Hudson, Lee, Miramontes, \& Portillo, 2001; Mokhoka, 2000; Orr, 2000). High levels of internalised stigma are associated with depression and lower levels of self-esteem (Berger, Ferrans, \& Lashley, 2 001; Eba, 2007; Santana \& Dancy, 2000). Depression may be a way of shutting down the emotional system so that it does not suffer dangerous overload (Giddens \& Giddens, 2000), although, depression can be dangerous, since it is often associated with suicide and can interfere with critical self-care behaviour such as adherence to antiretroviral therapy (Giddens \& Giddens, 2000; Safren, Hendriksen, Mayer, Mimiaga, Pickard, \& Otto, 2004). To assist women to deal with HIV it is necessary to facilitate change in their conception of HIV and their sense of self-worth. This research was initiated because there is hardly any documented literature available for practising psychologists to assist HIV-positive women to cope with the consequences of their diagnosis and stigma within the realities of the HIV\&AIDS epidemic in an African context.

The goal of the current research was to develop a therapeutic intervention to assist women to change their conception of HIV and their sense of self-worth and to empower them with more adaptive ways of thinking so as to deal with their experience of internalised and enacted stigma and in effect to enhance their health-seeking behaviour. Cognitive Behavioural Therapy (CBT) was regarded as an appropriate theoretical framework, because it is a structured, problem-orientated approach that uses cognitive and behavioural methods to challenge dysfunctional beliefs. It also promotes more realistic and adaptive ways of thinking in order to bring about emotional and behavioural change (Basco \& Rush, 2007; Beck, 1995; Zayfert \& Becker, 2007).

Beck's (1995) original cognitive model was used as guideline for this study. The model suggests that depressed mood states are accentuated by patterns of thinking that amplify mood shifts. 
Depressed people are mostly negative in how they see themselves, their world and their future, and demonstrate cognitive distortions such as to jump to negative conclusions, to over-generalise, to see things in all-or-nothing terms and to blame themselves to an excessive degree. These cognitive patterns are often based on dysfunctional underlying beliefs (such as "I am a bad person") activated by critical life events (Beck, Wright, Newman, \& Liese, 1993). CBT is directed towards alleviating cognitive biases and distortions and developing behavioural skills for coping. To the best of our knowledge there is no reported research that explores the effectiveness of CBT techniques in a population of African women with HIV. Through this research we will explore the appropriateness of CBT techniques which were developed in an individualistic context, with a group of African women.

The goal of the research was two-fold:

1. To develop a CBT programme for HIV-positive women based on an understanding of their experience of HIV and the related stigma, and

2. To evaluate the effectiveness of the programme.

\section{RESEARCH METHODS}

The research was conducted in two phases using a mixed method design.

\section{Phase 1: Development of the intervention model}

The following sources of information were used in an exploratory study to gain an understanding of the main issues that HIV-positive women face and the cognitive processes underlying their reactions. These data were obtained to inform the development of the intervention model.

Focus group discussions with practising psychologists. A focus group discussion was held with five clinical psychologists who had experience of working with HIV-positive women for more than seven years and were willing to participate in this study. The aim was to gather information about women's beliefs that influence their emotional reaction to HIV and how they cope. The interviewer used a semi-structured interview schedule and facilitated the discussion in English and seTswana. Thereafter the discussion was transcribed and translated into English with the assistance of two educators who teach English and seTswana at high-school level. Data were analysed qualitatively using Rubin and Rubin's (1995) method described below.

Interviews with HIV-positive women. Using an interview schedule, in-depth interviews were conducted with five HIV-positive women to develop an understanding of how they experience HIV, people's reaction towards them and how they cope with stigma. A purposive sampling technique was used where particular cases are chosen because of their relevance for the study (Strydom \& Venter, 2002). Nurses of the Wellness Clinic at the Witbank Hospital referred to the researcher five HIV-positive African women who were receiving treatment from the clinic and who experienced difficulties in dealing with stigma. The women were in their early to middle adulthood (aged 22 to 40), had been living with HIV for at least three months since diagnosis, had at least passed Grade 10 and came from a poor to average socio-economic background (household income of up to R6,000 per month). They spoke Nguni languages, seSotho or English fluently and consented to voluntary participation in the study. The interviews were tape-recorded, transcribed and translated into English.

Analysis of the data. The qualitative data of the interviews and focus group discussion were analysed using Rubin and Rubin's (1995) method of analysis. To enhance the validity and comprehensiveness of the interpretation, the two researchers interpreted the data separately. The researchers read and re-read the transcribed and translated interview data. They assigned a numerical code to each topic identified to be related to emotional experiences and ways of coping. Thereafter themes were identified by grouping together topics and concepts describing related ideas. The researchers assigned an alphabetical code to each theme. From this, overall themes were identified that enabled the researchers to interpret the data in the context of other theories or existing literature. The two 
researchers discussed their interpretations afterwards. Wherever differences in interpretation arose, consensus was reached after discussion.

The interpretation of interview and focus group data enabled the researchers to identify common themes in the experiences of HIV-positive women and to recognise significant misconceptions or irrational thought patterns. A summary of the themes identified is given here.

\section{Women's experiences of HIV and stigma}

Similar themes emerged from the interviews with HIV-positive women and focus group discussion with psychologists:

Feelings of powerlessness. HIV-positive women experienced irrational thoughts of failure, powerlessness and worthlessness. One woman expressed these feelings as follows: "My confidence has been lowered because I sometimes do not regard myself as a person."

Feelings of guilt and anger about the past. Women felt guilty and blamed themselves for contracting the virus, which often lead to self-destructive activities such as suicidal behaviour. One woman said: "I have regrets about my life; I often say that had I known that I was going to contract the virus, I would not have had sex." Others felt hurt and betrayed by their partners and perceived HIV as punishment from God. Some women generalised all negative feelings to be related to HIV.

Destructive behavioural patterns. W omen tended to pity, isolate and neglect themselves. One woman said: "My mood is low. I distance and isolate myself from others. I think that people are happy while I am sick."

Experience of the reaction of others. Women were scared that others might find out that they are HIV positive. They were afraid to lose their partners, and two women had in fact already lost their partners. One woman said that she feels uncomfortable when others talk about HIV: "I suddenly change as if I am not the same person. There is a thing that tells me that people know about my status and they are passing remarks to make me feel bad."

Uncertainty about the future. Women had a preconceived idea that HIV means death and that they were going to die soon. They were scared of death and the unknown, and one woman said: "I become so scared when I have to take medication. It is indeed true that I am going to die. That scares me."

These themes, which confirm previous research (Mokhoka, 2000; Orr, 2000; Skinner \& Mfecane, 2004), were used to develop the model of intervention.

\section{The intervention model}

A CBT model consisting of eight individual sessions was developed to address the five commonly identified themes that underlie the negative experiences of HIV-positive women. Women were challenged to change their way of thinking and to experiment with new behaviour. After each session, homework was assigned to facilitate change from one session to the next (Basco \& Rush, 2007). The intervention was adapted according to the needs of the women. The outline of the sessions was as follows:

Session 1: The role of HIV in their lives was explored through drawing life maps. They shared their experiences of living with HIV\&AIDS and the stigma they encountered. Intervention and homework assignment were aimed at symptom relief, to instil hope and to form a treatment alliance.

Session 2: Feelings of powerlessness and loss of self-worth were addressed by identifying underlying thoughts. Socratic questioning and reality testing (Moorey, 2000) were used to assist women to question the evidence of automatic thoughts, such as "Did you feel worthless before you knew your diagnosis? Why do you feel this way now?" Positive reframing was used to provide clients with alternative interpretations of HIV. Homework was assigned to identify negative automatic thoughts and assumptions relating to suicide, being bad or being to blame.

Session 3: Feelings of guilt, anger and negative self-evaluation were addressed. Therapy aimed 
to identify and change negative thought patterns and to replace it with more rational thoughts. The homework assignment was to reflect paradoxically on how feelings of guilt and self-pity could help to cope with her HIV-positive status.

Session 4: Destructive behaviour patterns such as self-pity, self-neglect, isolation, denial and suicide were addressed. The researcher challenged dysfunctional beliefs ("I am a bad person and deserve to die") and behaviour, such as self-neglect, and promoted more realistic adaptive ways of thinking ("I am a worthwhile person with positive and negative qualities"). New ways of coping through religion, social support and emotional expression were explored. Homework consisted of the listing of good qualities about themselves to replace negative assumptions.

Session 5: W omen were empowered to deal with stigma as they were taught basic human rights and anti-discriminatory laws. Positive reframing was used - for example, when people stigmatise them, it does not change them as people because they are still the same. Decatastrophising assists clients to imagine and prepare them for the worst thing that could happen if they disclosed their status (Moorey, 2000). Once their fear of disclosing had been confronted, women were assisted to disclose their status and to deal with interpersonal situations assertively (Albano \& DiBartolo, 2007). Homework tasks included the practising of assertiveness.

Session 6: Uncertainty about the future was addressed. W omen were taught stress management and alternative coping skills. They were tasked to set future goals for the next five to ten years.

Session 7: This session was scheduled to address the issues women were facing in changing their lifestyle. They could discuss successes and setbacks and they practised new skills through cognitive rehearsal to deal with setbacks.

Session 8: This session consolidated gains and assisted the participants in employing coping skills. Therapy was terminated during this session.

\section{Phase 2: Implementation and evaluation of the intervention model}

In the second phase of the research, the intervention model was implemented to evaluate its effectiveness. A sample of 20 black South African women living with HIV\&AIDS, who received ARV treatment from the Witbank Hospital and who experienced difficulties in dealing with stigma, were referred to the research. Selection criteria involved having lived with HIV for at least three months and having passed Grade 10. The women agreed to voluntarily participate in the research and were randomly assigned to the experimental and control group. The experimental group participated in eight weekly individual CBT sessions and the control group formed a waiting list group. An experimental design consisting of a pre-test/post-test control group was used to evaluate the intervention.

Data-gathering instruments. Both qualitative and quantitative methods were used. All the therapy sessions with the 10 participants were tape-recorded and transcribed in order to identify the reactions of participants to specific techniques used. The therapist's process notes of each session with each woman were used as participative observation notes of the progress in therapy.

Five psychometric instruments were administered pre- and post-therapy to assess possible change quantitatively:

The Brief Cope Scale (Carver, 1997) is a 14-scale/28-item questionnaire that utilises Lazarus and Folkman's (1984) model of coping behaviour. Response options range from 0 (I haven't been doing this at all) to 3 (I've been doing this a lot). Carver (1997) reported the soundness of the internal structure of the scale through factor analysis. This scale was used in South Africa to assess coping of HIV positive women. Factor analysis of data for 317 women revealed two factors: positive coping (e.g. positive reframing, religion and acceptance) and negative coping (e.g. denial, substance abuse and self-blame). The reliability coefficient for this sample was .63 for the scale as a whole; .75 for positive coping; and .54 for negative coping (Makin et al., 2008).

The Serithi Internalised Stigm a Scale was developed for use in South African samples (Visser 
et al., 2008). The scale consists of 16 questions rated on a 4-point Likert-type scale to assess the person's own experience of stigma. A high total score indicates the experience of high levels of stigma. Factor analysis with the data of 317 HIV-positive women, revealed two factors: a tendency towards self-blame and interpersonal distance. The Cronbach alpha coefficient for the scale was .72 (Makin et al., 2008).

Enacted Stigm $\boldsymbol{a}$ is the actual experience of stigma in relationships. Participants had to indicate on a 3-point scale (no experience, experienced, and a lot of experience) the level of experience of 11 types of behaviour that could be discriminative such as avoiding interaction, ending a relationship, and forms of verbal and physical abuse. A scale score is calculated for level of exposure (Visser \& Makin, 2004).

The Rosenberg Self-Esteem Scale (RSES) is a widely used self-esteem measure consisting of 10 questions (Rosenberg, 1979) that measure the extent to which one values and feels content with oneself. Participants indicate their level of agreement on a 4-point Likert-type scale. Sullivan (2001) found a test-retest reliability of .82 and Makin et al. (2008) reported a Cronbach alpha coefficient of .75 for the South African sample of HIV-positive women. A high degree of convergent validity was reported when the RSES was correlated with other measures of self-esteem (Adkins, 2003).

The Beck Depression Inventory-II (BDI-II) is the most widely used and best validated rating scale for the assessment of depression. It has been widely used in South Africa and the psychometric equivalence established. It addresses all nine of the symptom criteria listed for major depressive episode (American Psychiatric Association, 1994). This scale consists of 21 groups of statements that assess the severity of depressive symptoms (Beck, Steer, \& Brown, 1996). The participant is requested to pick out one statement in each group that best describes the way he/she has been feeling the past two weeks, each carrying a weight ranging from 0 (normal) to 3 (most severe) (Beck et al., 1996). Scores can be interpreted in terms of well-developed guidelines. Internal consistency coefficients for the BDI-II ranged between .82 and .93 for an outpatient population consisting of 9,168 respondents (Alansari, 2006).

Data analysis. The qualitative data gained from therapy transcripts and process notes were analysed using Rubin and Rubin's (1995) method described in phase 1. The researcher focused on women's progress in therapy (outcome) and their reaction to the various CBT techniques. The frequency of use of specific techniques was noted, as well as the number of clients with whom each technique was used effectively. Techniques were regarded as effective when women understood what was meant, reflected on their own thoughts and could change aspects of their thinking during the session or in the session directly thereafter.

The psychometric data were analysed by using the non-parametric Mann-Whitney test, given the small sample size (Mendenhall, Beaver, \& Beaver, 2003). Firstly, the pre-tests were analysed to assess whether the groups were equivalent before the intervention. Change scores between pre-test and post-test were compared between the experimental and control groups to evaluate change as a result of the intervention.

The research was ethically approved by the Ethics Committee of the Faculty of Humanities, University of Pretoria and the Provincial Government of Mpumalanga. Participation was voluntary, with informed consent of participants. Participants in the control group received psychotherapy upon completion of the study.

\section{RESULTS}

\section{Outcome of the intervention}

The pre- and post-test scores of the psychometric scales were analysed using Mann-Whitney tests (Table 1).

Before the intervention, no significant differences were found on the five scales between the experimental and control group. The two groups can therefore be considered similar. 
Table 1. Comparison of experimental and control group scores

\begin{tabular}{lccc}
\hline & $\begin{array}{c}\text { Experimental group } \\
(N=10) \\
\text { Mean }(S D)\end{array}$ & $\begin{array}{c}\text { Control group } \\
(N=10) \\
\text { Mean }(S D)\end{array}$ & Mann Whitney \\
\hline Comparison of pre-test scores & & & \\
Coping negative (Brief Cope) & & & \\
Coping positive (Brief Cope) & $20.3(7.4)$ & $22.5(4.3)$ & 44.5 \\
Internalised stigma & $37.0(6.7)$ & $33.2(9.6)$ & 61.0 \\
Enacted stigma & $37.7(6.8)$ & $42.4(6.8)$ & 33.0 \\
Self-esteem (RSE) & $5.9(3.9)$ & $6.1(4.0)$ & 48.5 \\
Depression (BDI-II) & $8.5(4.3)$ & $9.6(7.1)$ & 49.0 \\
& $28.1(12.7)$ & $24.3(6.2)$ & 54.5 \\
Comparison of change scores after intervention & & \\
Change in coping negative (Brief Cope) & $7.8(6.9)$ & $0.1(3.4)$ & $80.5^{*}$ \\
Change in coping positive (Brief Cope) & $6.4(4.8)$ & $0.7(5.3)$ & $76.5^{*}$ \\
Change in internalised stigma & $-15.1(7.7)$ & $-6.1(7.1)$ & $19.5^{*}$ \\
Change in enacted stigma & $-2.1(3.9)$ & $-1.0(3.5)$ & 41.0 \\
Change in self-esteem (RSE) & $-7.8(4.3)$ & $-2.2(2.7)$ & $14.0^{* *}$ \\
Change in depression (BDI-II) & $-19.2(9.8)$ & $-0.6(5.9)$ & $3.0^{* * *}$ \\
\hline
\end{tabular}

* $p<0.05 ; * * p<0.01 ; * * * p<0.001$

To determine the effect of the intervention, change scores were calculated before and after the intervention for each individual. The Mann-Whitney test was used to determine whether the experimental group's scores had changed significantly more than those of the control group. After the intervention, significant differences were found in the change scores of the two groups for four of the five scales. This means that the women in the experimental group reported less negative ways of coping ( $p<0.05)$, lower depression $(p<0.001)$ and lower internalised stigma $(p<0.05)$, as well as more positive ways of coping $(p<0.05)$ and higher levels of self-esteem $(p<0.01)$ than the control group. There was no change in the enacted stigma scores in both groups. It can therefore be concluded that, compared to the control group, women in the intervention group showed more positive change.

\section{Qualitative evaluation}

The qualitative evaluation focused on the reactions of women in therapy. Change in thought patterns and behaviour was observed in all of the women. They grasped that HIV will not cause their immediate death and that they can still live a healthy life. This was the start of the change process for seven of the women. Their self-perception changed and the way they interpreted others' perception of them. Women regained control over their lives through the realisation that although they cannot change the diagnosis, they have control over their thoughts, feelings and behaviour. While HIV was seen as the centre of their lives before therapy, they could carry on with their lives after therapy. One woman said: “... I came to realise that I am not a failure in life. I am not different from other people. My life goes on as I wish it to ..."

Once the women accepted their status, they started exchanging their personal experience with others and teaching them about HIV. Five of the women disclosed their status to partners or family, despite expectations of being stigmatised. This played a pivotal role in their lives, since it helped them to reappraise their situation and to find alternative ways of coping. One woman said: "I want to live and accomplish my goals by taking care of myself and educating others about the disease." At the end of the sessions nine of the women rediscovered their meaning in life. One woman pointed 
out: "I wanted to die, because I am useless due to the disease. However, I have come to realise that my life, my children and the family are important."

Despite many positive changes observed, two women benefited less from the intervention. They did not fully participate because they were preoccupied with their ill health and were probably coping by refusing to deal with their feelings.

\section{The effectiveness of CBT techniques}

Through the study of therapy transcripts, the effectiveness of CBT techniques could be evaluated. Table 2 demonstrates the perceived effectiveness of each of the techniques used with specific clients.

Table 2. Summary of the perceived effectiveness of various techniques

\begin{tabular}{lccc}
\hline \multicolumn{1}{c}{ Techniques } & $\begin{array}{c}\text { Number of clients that } \\
\text { technique was used with }\end{array}$ & $\begin{array}{c}\text { Frequency } \\
\text { effective }\end{array}$ & $\begin{array}{c}\text { Frequency } \\
\text { not effective }\end{array}$ \\
\hline Positive cognitive reframing & 10 & 10 & 0 \\
Teaching coping strategies & 10 & 10 & 0 \\
Homework assignments & 10 & 8 & 2 \\
Decatastrophising & 10 & 10 & 0 \\
Assertiveness training & 10 & 8 & 2 \\
Identifying, challenging and changing & 9 & 6 & 3 \\
underlying negative automatic thoughts & & & \\
and assumptions & 7 & 4 & 3 \\
Problem-solving skills & 7 & 2 & 5 \\
Socratic questioning and reality testing & 5 & 3 & 2 \\
Education about HIV\&AIDS & 3 & 1 & 2 \\
Positive self-statement logs & &
\end{tabular}

Techniques that were mostly effective were the following:

Positive cognitive reframing challenged dysfunctional beliefs such as "being HIV-positive means that one is worthless" and provided alternative interpretations of HIV. This was effective in changing the way women perceived themselves and HIV and to feel more in control of their situation. For example, one woman realised that she was no different from other people, which opened new opportunities for her. She started to seek employment, to date and to live a normal life.

Introducing different coping strategies such as religion, social support, thinking differently and emotional expression, was perceived to make a difference in women's lives. Support groups provided the opportunity to unload their emotions and to feel good about themselves, rather than to pity themselves.

Decatastrophising, a method of anticipating and dealing with negative thoughts, played a significant role in modifying irrational fears of being stigmatised. Women realised that when fear is confronted, it often becomes manageable. One woman said: "People are of course going to talk when you live with this disease - so I am ready for such talk."

Homework assignments that were successfully completed facilitated positive thoughts instead of ruminating on negative automatic thoughts between therapy sessions.

Assertiveness training empowered women to deal with interpersonal problems with their children and partners and assisted them to deal with stigmatising reactions. Its effectiveness was demonstrated by women who no longer withdrew from social relationships, but talked to neighbours about HIV. Two women did not benefit from assertiveness training — it may take more time for some to acquire these skills.

Problem-solving skills assisted women to regard problems as challenges, rather than attribute 
them to their diagnosis.

Some of the more advanced cognitive strategies, such as identifying and monitoring negative automatic thought patterns, and Socratic questioning were not effective with all of the women.

\section{DISCUSSION}

The study revealed that being HIV-positive and trying to cope with stigma involves diverse experiences, although there were common themes for all participants. They experienced feelings of worthlessness, guilt and anger, fear about the future, they anticipated being stigmatised and had behaviour detrimental to their own health. These results confirm findings of similar research (Mokhoka, 2000; Orr, 2000; Skinner \& Mfecane, 2004). Therapy therefore had to assist women to change their perception of HIV and internalised stigma.

The CBT intervention consisting of eight individual therapy sessions aimed at changing distorted thought patterns underlying the women's dysfunctional reaction to HIV. An outcome evaluation showed that women who participated in therapy had improved significantly on the psychometric scales, in comparison to a similar control group. The experimental group's level of depression after therapy was significantly lower than that of the control group. The average depression score of women who received therapy was in the range of 'normal ups and downs' (scores of 0-10), compared to 'moderate to severe depression' before the therapy (scores 30-40) (Beck et al., 1996). The experimental group reported significant increases in positive coping after therapy, such as constructive thoughts and positive lifestyle changes. They also reported less negative coping, such as criticising themselves. The elevation in the women's self-esteem could possibly be contributed to their improved positive coping after having participated in therapy (Wiser, Goldfried, Raue, \& Vakoch, 1996).

While internalised stigma was high before the intervention, the experimental group reported significantly lower scores after therapy, compared to the control group. While most of them initially denied living with the virus, they accepted their status after therapy and five women actually disclosed their status and educated others about the disease. These changes can be attributed to the cognitive reframing techniques used (Zayfert \& Becker, 2007). On the other hand, levels of enacted stigma did not change, possibly because the questions in the post-test did not specify experiences since the start of therapy. It is debatable whether therapy would make a difference in the community's reaction towards the clients. Though, once people feel confident, others may act differently towards them and clients may handle situations differently.

The quantitative data therefore showed that the intervention had a positive impact on the women's ability to cope with HIV and the related stigma. The same patterns of positive change were observed in the qualitative data on the women's reactions during therapy. Though it was a small sample of women participating in the research, the use of different methods to obtain comparable results increased the validity of the results.

Of specific importance is the qualitative evaluation, which allowed conclusions about the value of specific $\mathrm{CBT}$ techniques in an African context. Positive cognitive reframing and decatastrophising (cognitive techniques), and training in coping and assertiveness skills (behavioural techniques) were effective in facilitating change. Complex cognitive techniques such as identifying underlying automatic thoughts and Socratic questioning were not effective with all the women. Perhaps it was used too early in the therapy or the women did not have the intellectual or self-reflective capacity to accomplish this. More time would be needed or it could be used later on in therapy, when clients have developed self-reflective skills.

Some of the women were able to change negative thought patterns when the therapist highlighted these patterns. But the researchers doubt if clients were equipped with the ability to manage their own negative thought patterns outside the therapy situation (Basco \& Rush, 2007), since it may require more time to incorporate these techniques as part of one's cognitive repertoire. 
Despite the fact that this study succeeded in providing an intervention model that resulted in change in various psychological variables, there were limitations that could have affected the validity of the results. The study was conducted with a selected group of black women in an urban area and who had access to medical treatment. The findings can therefore not be generalised to all women though generalisation was not the aim of the study. The study design was very basic involving two groups and a pre-post assessment. The design does not control for differential effects which may be a threat to internal validity (Gravetter \& Forzano, 2009). Additionally, the study did not include follow-up evaluation. One can therefore not determine the duration of the positive results obtained in the experimental group.

The 'researcher effect' may have had a prominent effect, since it was a male researcher dealing with a gendered problem. Despite the possible influence, the intimate nature of the participants' disclosure indicated that the relationship was constituted in a professional way. The dual role of being researcher and therapist may also have impacted on the quality of the therapy and the research results. The researcher was very involved in the therapeutic process and his "eagerness" to see results created anxiety for the therapist that could have influenced the clients. The researcher's involvement in the therapy could also have had an effect in the interpretation of the data. To account for this limitation the qualitative data were interpreted by two researchers who reached consensus about their interpretation. A preferred practice will be to separate the role of researcher from that of the therapist by training practitioners to implement the therapy.

The research illustrates one of the dilemmas of research in psychotherapy. For the research to be valid, the therapy should be presented in a structured way, similar for all the clients. For therapy to be effective, the specific needs of the clients should be addressed. The structured intervention implemented in this research may therefore have failed to address some of the specific individual needs of the clients.

The CBT intervention model can be recommended to empower HIV-positive women to deal with HIV and internalised stigma. The model can be used in a structured way, but with appropriate flexibility to deal with the client's problems rather than to adhere to the model strictly (Basco \& Rush, 2007; Zayfert \& Becker, 2007).

The successful implementation of CBT also relies on the level of cognitive ability of clients to reflect on their own functioning. When cognitive techniques do not provide the expected results, more behavioural techniques may be included.

In future implementation, the techniques that worked well in this research (e.g. positive cognitive reframing, coping strategies) could be implemented, rather than using too many and too complex techniques. If the technique does not facilitate successful change the first time, it could be repeated to guide the client towards change. The first exposure can start the change process that may have an impact in later sessions. Techniques that were used with less positive results (e.g. identifying and changing underlying automatic thoughts, Socratic questioning) were complex techniques that may need more time to understand.

This research is of practical value to provide practitioners with an understanding of the experiences of HIV-positive women and a therapeutic model to assist women in dealing with HIV and stigma. The research also contributes to showing how to effectively implement CBT techniques with a group of African women and how these techniques can contribute to change in the latter's wellbeing.

\section{REFERENCES}

Abdool Karim, Q. (2005). Heterosexual transmission of HIV — the importance of a gendered perspective in HIV prevention. In S.S. Abdool Karim \& Q. Abdool Karim (Eds), HIV/AIDS in South Africa. Cape Town: Creda Communications.

Adkins, K.L. (2003). Predicting self-esteem based on perceived parental favoritism and birth order. Unpublished Master's Dissertation. East Tennessee State University. 
Alansari, B.M. (2006). Internal consistency of an Arabic adaptation of the Beck Depression Inventory-II with college students in eighteen Arab countries. Social Behavior and Personality. Retrieved from: http://findarticles.com/p/articles/mi_qa3852/is_200601/ai_n17175080

Albano, A.M., \& DiBartolo, P.M. (2007). Cognitive-behavioral therapy for social phobia in adolescents: Stand up, speak out, therapist guide. New York: Oxford University Press.

American Psychiatric Association. (1994). Diagnostic and statistical manual of mental disorders. (4th ed.). Washington, DC.

Basco, M.R., \& Rush, A.J. (2007). Cognitive-behavioral therapy for bipolar disorder. (2nd ed.). New York: The Guilford Press.

Beck, A.T., Steer, R.A., \& Brown, G.K. (1996). Manual for the Beck Depression Inventory-II. San Antonio, TX: Psychological Corporation.

Beck, A.T., Wright, F.D., Newman, C.F., \& Liese, B.S. (1993). Cognitive therapy of substance abuse. New York: The Guilford Press.

Beck, J.S. (1995). Cognitive therapy: Basics and beyond. New York: The Guilford Press.

Berger, B., Ferrans, C.E., \& Lashley, F.R. (2001). Measuring stigma in people with HIV: Psychometric assessment of the HIV stigma scale. Research in Nursing and Health, 24, 518-529.

Bond, V., Chase, E., \& Aggleton, P. (2002). Stigma, HIV/AIDS and prevention of mother-to-child transmission in Zambia. Evaluation and Program Planning, 25, 347-356.

Carver, C.S. (1997). You want to measure coping but your protocol's too long: Consider the Brief COPE. International Journal of Behavioral Medicine, 4, 92-100.

Deacon, H., Stephney, I., \& Prosalendis, S. (2005). Understanding HIV/AIDS stigma: A theoretical and methodological analysis. Cape Town: HSRC Press.

Eba, P.M. (2007). Stigma(ta), re-exploring HIV-related stigma. AIDS Review. Pretoria: Centre for the Study of AIDS, University of Pretoria.

Giddens, S., \& Giddens, O. (2000). Coping with grieving and loss. New York: The Rosen Publishing Group.

Goffman, E. (1963). Stigma: Notes on the management of spoiled identity. Englewood Cliffs (NJ): Prentice-Hall.

Gravetter, F.J., \& Forzano, L.B. (2009). Research methods for the Behavioral Sciences. Wadsworth.

Green, G. (1995). Attitudes towards people with HIV: Are they as stigmatizing as people with HIV perceive them to be. Social Science and Medicine, 41, 557-568.

Hudson, A.L., Lee, K.A., Miramontes, H., \& Portillo, C.J. (2001). Social interactions, perceived support and level of distress in HIV-positive women. Journal of the Association of Nurses in AIDS Care, 12, 68-76.

Lazarus, R.S., \& Folkman, S. (1984). Stress, appraisal and coping. New York: Springer.

Mah, T.L., \& Halperin, D.T. (2008). Concurrent sexual partnerships and the HIV epidemics in Africa: Evidence to move forward. AIDS and Behaviour, 22 July.

Makin, J.D., Forsyth, B.W.C., Visser, M.J., Sikkema, K.J., Neufeld, S., \& Jeffery, B. (2008). Factors affecting disclosure in South African HIV-positive pregnant women. AIDS Patient Care and STDs, 22, 907-916.

Mendenhall, W., Beaver, R.J., \& Beaver, B.M. (2003). Introduction to probability and statistics. (11th ed.). Pacific Grove, CA: Brooks/Cole-Thompson.

Mokhoka, M.D. (2000). Black women diagnosed as HIV positive: Their psychological experiences and coping mechanisms. Pretoria: University of Pretoria.

Moorey, S. (2000). Cognitive therapy. In W. Dryden (Ed.). Handbook of individual therapy. London: SAGE Publications.

Morrison, M.F., Petitto, J.M., Ten Haven, T., Gettes, D.R., Chiappini, M.S., \& Weber, A.L. (2002). Depressive and anxiety disorder in women with HIV infection. American Journal of Psychiatry, 159, 789-796.

Orr, N.M. (2000). Positive health. (2nd ed.). Nelspruit: Creda Communications.

Parker, R., \& Aggleton, P. (2003). HIV and AIDS-related stigma and discrimination: A conceptual framework and implications for action. Social Science and Medicine, 57, 13-24.

Rohleder, P., \& Gibson, K. (2006). 'We are not fresh': HIV-positive women talk of their experience of living with their 'spoiled identity'. South African Journal of Psychology, 36, $25-44$.

Rosenberg, M. (1979). Conceiving the self. New York: Basic Books, Inc. 
Ross, E. (2004). Women's rights crucial to AIDS fight, U.N. says: Inequality is seen as making females the virus's main victims in developing nations. Associated Press, 23 November.

Rubin, H.J., \& Rubin, I.S. (1995). Qualitative interviewing: The art of hearing data. Thousand Oaks: SAGE Publications.

Safren, S.A., Hendriksen, E.S., Mayer, K.H., Mimiaga, M.J., Pickard, R., \& Otto, M.W. (2004). Cognitive-behavioral therapy for HIV medication adherence and depression. Cognitive and Behavioral Practice, 11, 415-423.

Santana, M.A., \& Dancy, B.L. (2000). The stigma of being named “AIDS carriers" on Haitian-American women. Health Care for Women International, 21, 161-171.

Scambler, G., \& Hopkins, A. (1986). Being epileptic, coming to terms with stigma. Sociology of Health and Illness, 8, 26-43.

Siyam'kela. (2004). Siyam 'kela: Measuring HIV/AIDS related stigma. A joint project of the POLICY Project, South Africa; Centre for the Study of AIDS, University of Pretoria; United States Agency for International Development (USAID) and Chief Directorate: HIV/AIDS \& TB, Department of Health, March. Retrieved from: www.policyproject.com

Skinner, D., \& Mfecane, S. (2004). Stigma, discrimination and implications for people living with HIV/AIDS in South Africa. Journal of the Social Aspects of HIV/AIDS, 1, 157-164.

Strydom, H., \& Venter, L. (2002). Sampling and sampling methods. In A.S. de Vos (Ed.), H. Strydom, C.B. Fouché \& C.S.L. Delport. Research at grass roots: For the social sciences and human services professions. (2nd ed.). Pretoria: Van Schaik Publishers.

Sullivan, S. (2001). The relations between emotional stability, self-esteem and sense of coherence. Retrieved from: http://alpha.fdu.edu/psychweb/Vol16/Sullivan.pdf

United Nations Programme on HIV/AIDS. (2007). AIDS epidemic update, December. Retrieved from: http://data.unaids.org/pub/EPISlides/2007/2007_epiupddate_en.pdf

Van Dyk, A.C. (2008). HIVAids care \& counselling: A multidisciplinary approach. Cape Town: Pearson Education.

Visser, M.J., Kershaw, T., Makin, J.D., \& Forsyth, B.W.C. (2008). Development of parallel scales to measure HIV-related stigma. AIDS and Behavior, 12, 759-771.

Visser, M.J., \& Makin, J.D. (2004). HIV+ women's experience of stigma and social support. Presented at the second African conference on social aspects of HIV/AIDS research, Cape Town, South Africa.

Wiser, S.L., Goldfried, M.R., Raue, P.J., \& Vakoch, D.A. (1996). Cognitive-behavioral and psychodynamic therapies: A comparison of change processes. In W. Dryden (Ed.), Research in counselling and psychotherapy: Practical applications. London: SAGE Publications.

Zayfert, C., \& Becker, C.B. (2007). Cognitive-behavioral therapy for PTSD: A case formulation approach. New York: The Guilford Press. 